Supporting Information

\title{
High volumetric capacity three-dimensionally sphere-caged secondary battery anodes
}

Jinyun Liu, ${ }^{\dagger,+}$ Xi Chen, ${ }^{\zeta}$ Jinwoo Kim,,${ }^{ \pm}$Qiye Zheng, ${ }^{t}$ Hailong Ning, ${ }^{4}$ Pengcheng Sun,,${ }^{+}$Xingjiu

Huang, ${ }^{\dagger}$ Jinhuai Liu, ${ }^{\dagger}$ Junjie Niu, ${ }^{\zeta}$ and Paul V. Braun*, ${ }^{*}$

${ }^{\dagger}$ Nanomaterials and Environmental Detection Laboratory, Institute of Intelligent Machines, Chinese Academy of Sciences, Hefei, Anhui 230031, China.

* Department of Materials Science and Engineering, Department of Chemistry, Frederick Seitz Materials Research Laboratory, and Beckman Institute for Advanced Science and Technology, University of Illinois at Urbana-Champaign, Urbana, Illinois 61801, USA.

${ }^{\Delta}$ Xerion Advanced Battery Corp., Champaign, Illinois 61820, USA.

${ }^{\zeta}$ Department of Materials Science and Engineering, University of Wisconsin-Milwaukee, Milwaukee, Wisconsin 53201, USA.

* Correspondence should be addressed to P.V.B. (E-mail: pbraun@illinois.edu). 

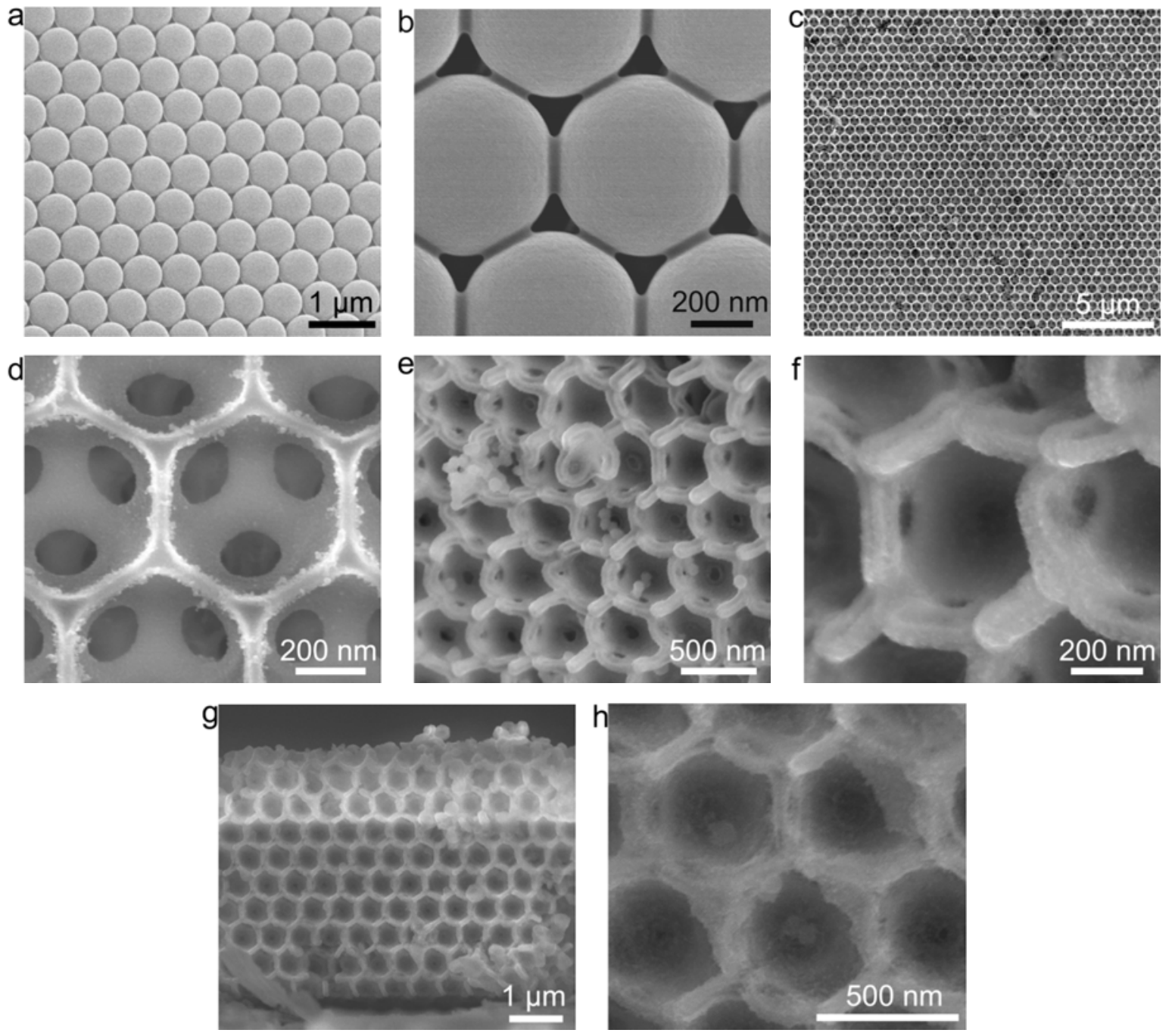

Figure S1. (a) Cross section and (b) top-view SEM images of the PS opal after heating at $95{ }^{\circ} \mathrm{C}$ for 3 h. (c) Low- and (d) high-magnification top-view SEM images of the $\mathrm{SnO}_{2}$ inverse opal after removing the PS opal template. (e) Low- and (f) high-magnification cross-sectional SEM images of the $\mathrm{SnO}_{2} @ \mathrm{SiO}_{2} @ \mathrm{SnO}_{2}$ inverse opal obtained after hydrothermal growth of $\mathrm{SnO}_{2}$ onto the $\mathrm{SiO}_{2}$-coated $\mathrm{SnO}_{2}$. (g) Low- and (h) high-magnification cross-sectional SEM images of the final nanocomposite anode. 


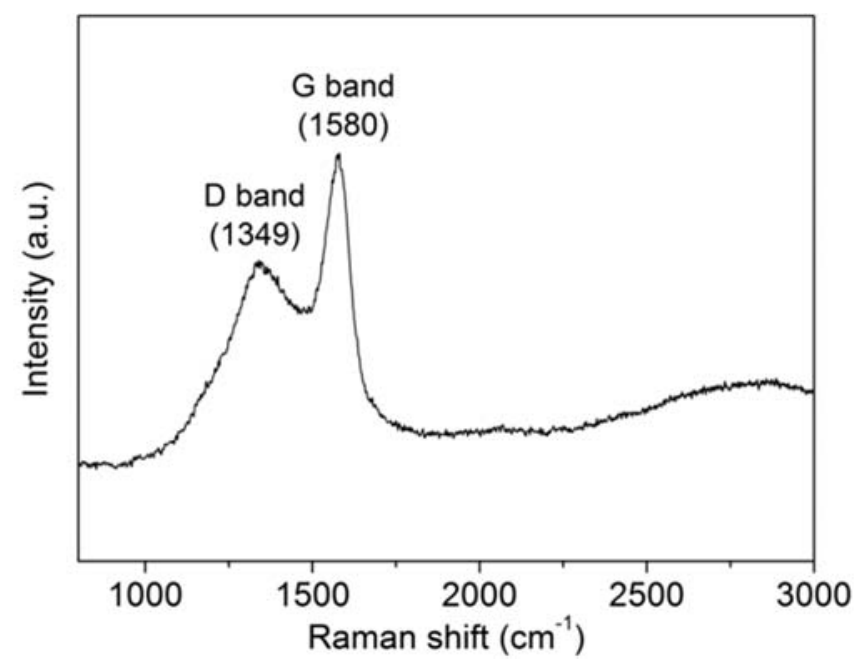

Figure S2. Raman spectrum of the nanocomposite anode. Peaks at about 1349 and $1580 \mathrm{~cm}^{-1}$ can be assigned to the $s p^{3}$ and $s p^{2}$-bonded carbon ${ }^{1}$, respectively.

Thermogravimetric analysis (TGA). The $\sim 10 \%$ weight loss between room temperature and $100{ }^{\circ} \mathrm{C}$ can be ascribed to the evaporation of absorbed moisture (Figure S3). The weight increase after that is attributed to the combined effect of the oxidation of $\mathrm{Sn}$ and carbon combustion into $\mathrm{CO}_{2}$. Since the weight at $500{ }^{\circ} \mathrm{C}\left(\mathrm{SnO}_{2}\right)$ is about $109 \%$ of the initial sample, after taking into account the water content, the $\mathrm{Sn}$ content of the $\mathrm{Sn} / \mathrm{C}$ anode is calculated to be $\sim 95 \%$; while the carbon is about $5 \%$ calculated as followed (carbon content calculated here):

$$
\begin{aligned}
\mathrm{C}(\%) & =1-\mathrm{Sn}(\%) \\
& =1-\frac{\mathrm{SnO}_{2} \text { mass }}{\mathrm{SnO} \mathrm{O}_{2} \text { molecular weight }} \times(\text { Sn molecular weight }) \\
& =1-\frac{\frac{109 \%}{150.7} \times 118.7}{1-10 \%} \times 100 \% \\
& \approx 5 \%
\end{aligned}
$$




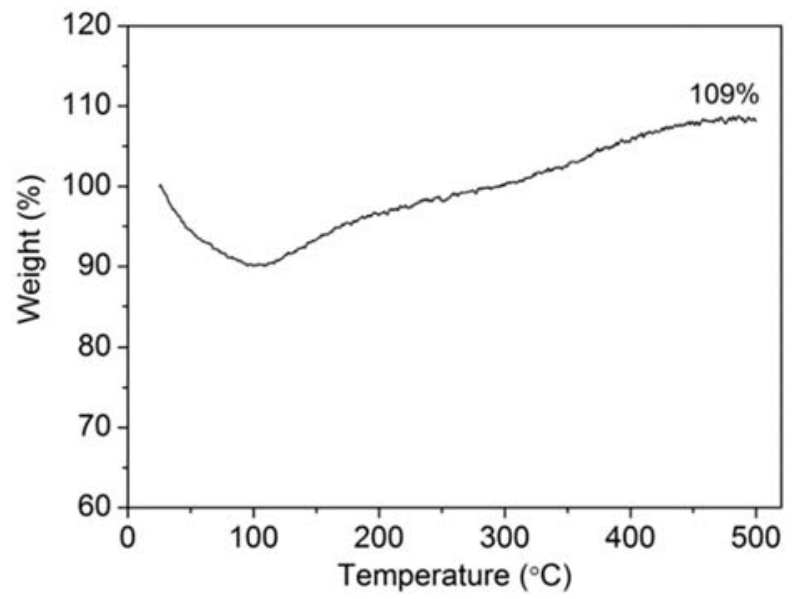

Figure S3. TGA curve of the Sn-based nanocomposite anode (heated at $10{ }^{\circ} \mathrm{C} \mathrm{min}^{-1}$ in air).

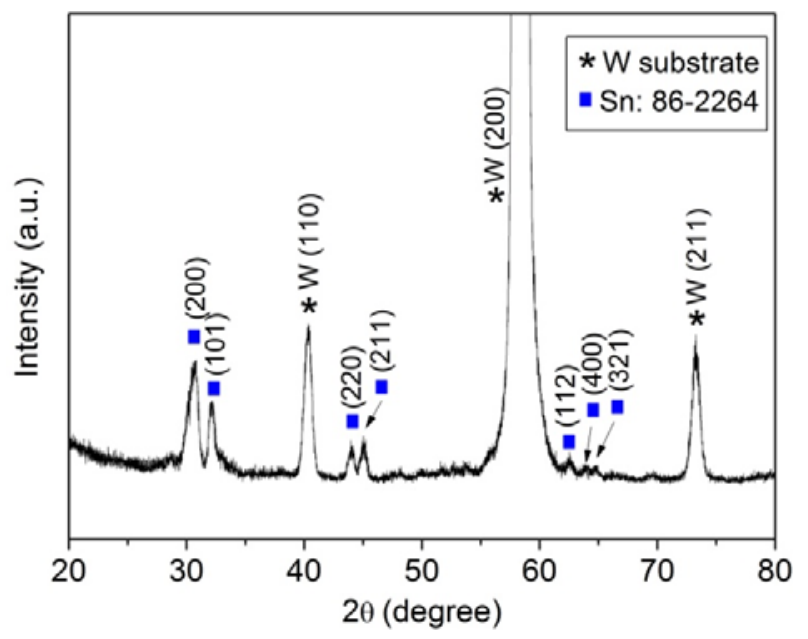

Figure S4. XRD pattern of the Sn-based nanocomposite anode. 


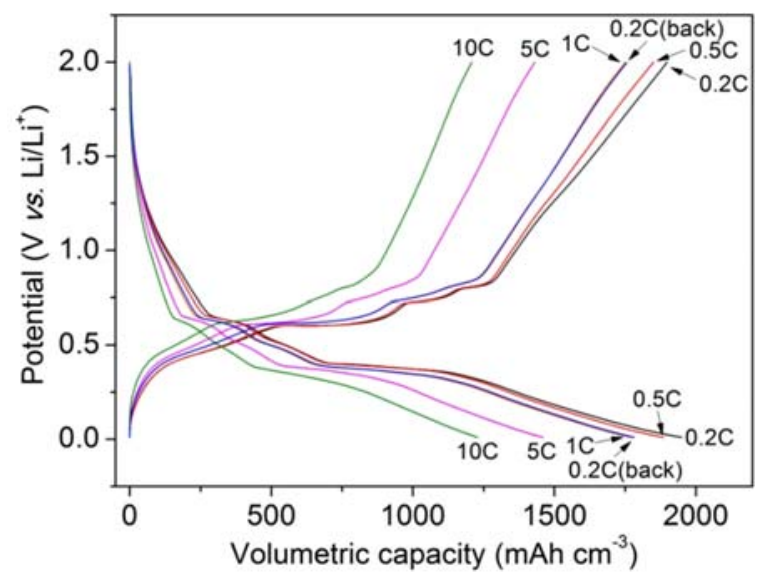

Figure S5. Galvanostatic discharge-charge cycles of the Sn-based nanocomposite anode ran at a series of increasing $\mathrm{C}$-rates from $0.2 \mathrm{C}$ to $10 \mathrm{C}$ followed by $0.2 \mathrm{C}$ cycles. At each $\mathrm{C}$-rate, the anode was cycled 10 times. The plot is from the last cycle at each C-rate.
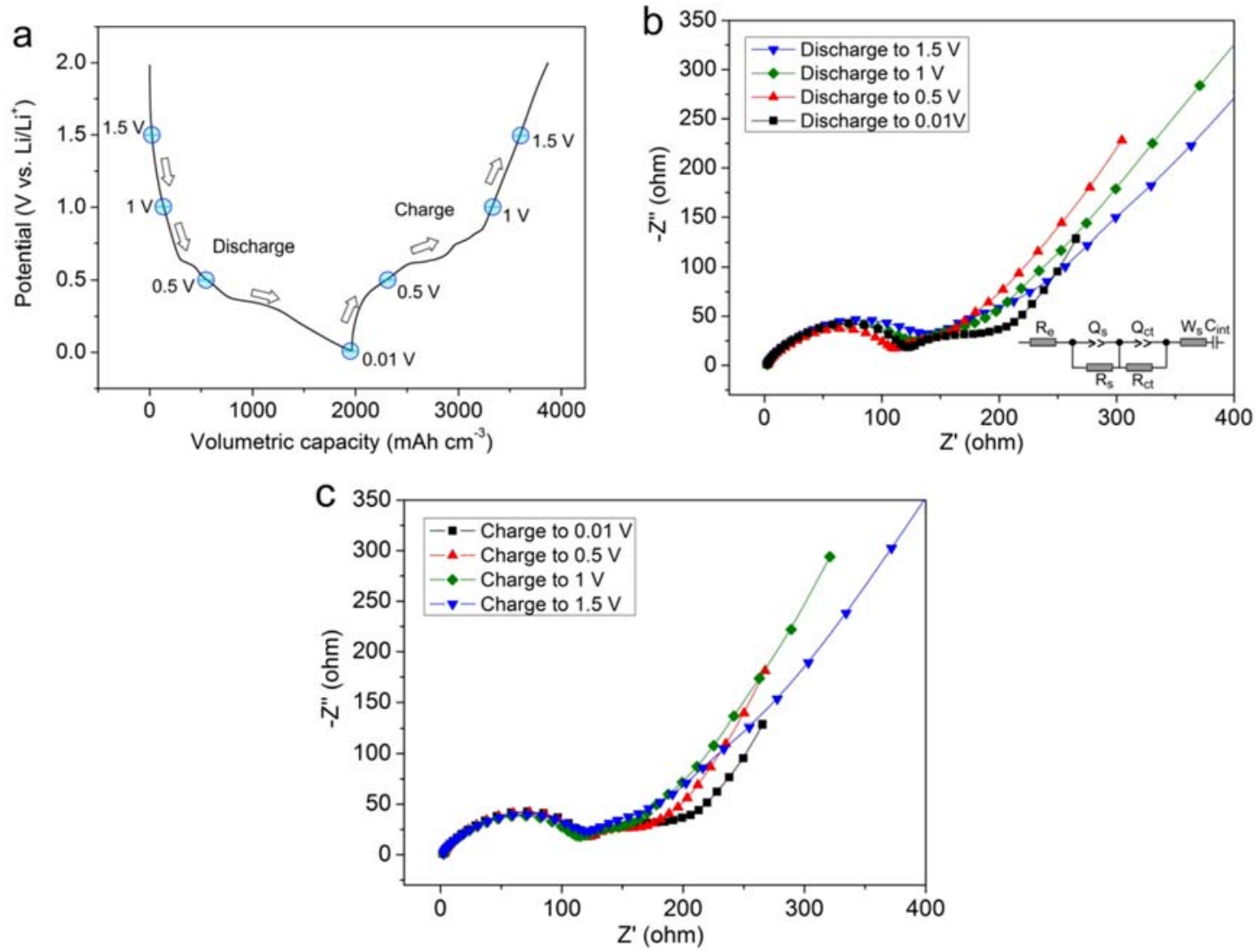

Figure S6. (a) Illustration for the impedance measurements at different potentials during a 
discharge-charge cycle. (b) Nyquist plots of the 3D sphere-caged $\mathrm{Sn} / \mathrm{C}$ anode discharged to 1.5, 1 , 0.5 , and $0.01 \mathrm{~V}$. Inset is the equivalent circuit used for fitting which contains the electrolyte resistance $\left(R_{\mathrm{e}}\right)$, surface film $\left(R_{\mathrm{s}}\right)$ and charge transfer $\left(R_{\mathrm{ct}}\right)$ resistances, a constant phase element involving a double layer capacitance, and a Warburg impedance $\left(W_{\mathrm{s}}\right)$ related to solid-state diffusion of lithium in the anode. (c) Nyquist plots of the electrode charged to $0.01,0.5,1$, and $1.5 \mathrm{~V}$. The discharge-charge process ran over the potential range of 2 to $0.01 \mathrm{~V}$. The cycling rate was $0.5 \mathrm{C}$, and the frequency range applied was $100 \mathrm{kHz}$ to $0.01 \mathrm{~Hz}$.

Table S1. Fitting results from the Nyquist plots of the Sn-based nanocomposite anode lithiated and delithiated between 2 and $0.01 \mathrm{~V}$.

\begin{tabular}{lccc}
\hline & $R_{\mathrm{e}}(\Omega)$ & $R_{\mathrm{S}}(\Omega)$ & $R_{\mathrm{ct}}(\Omega)$ \\
\hline Discharge to $1.5 \mathrm{~V}$ & 4.53 & 51.32 & 235.59 \\
Discharge to 1 V & 4.36 & 46.51 & 202.1 \\
Discharge to $0.5 \mathrm{~V}$ & 4.62 & 43.68 & 116.3 \\
Discharge to $0.01 \mathrm{~V}$ & 4.83 & 42.01 & 89.68 \\
Charge to $0.5 \mathrm{~V}$ & 4.65 & 44.43 & 106.51 \\
Charge to $1 \mathrm{~V}$ & 4.54 & & 263.64 \\
\hline
\end{tabular}


Thick electrode fabrication. As shown in Figure S7, 3D porous Ni scaffolds obtained from Xerion Advanced Battery Corp ( $\sim 5$ vol.\% filling fraction; $\sim 100 \mu$ m-thick) were first coated with a $\mathrm{SiO}_{2}$ layer through a Stöber process. Typically, $10 \mathrm{~mL}$ of Millipore water and $2.5 \mathrm{~mL}$ of ammonium hydroxide (28-30\% $\mathrm{NH}_{3}$ basis, Sigma-Aldrich Corp.) were mixed with $40 \mathrm{~mL}$ of ethanol. Then, a Ni scaffold held by an extended clamp was immersed into the solution. $1 \mathrm{~mL}$ of tetraethylorthosilicate (TEOS, Sigma-Aldrich Corp.) was added dropwise into the solution under constant magnetic stirring. After $2 \mathrm{~h}$, the scaffold was removed, washed with ethanol and water, and dried at $60{ }^{\circ} \mathrm{C}$. The obtained $\mathrm{SiO}_{2}$-coated scaffolds were used as substrates for the subsequent hydrothermal growth of $\mathrm{SnO}_{2}$, followed by carbon coating, and reducing treatment, using the same procedures presented in the Experimental Section for the $\mathrm{Sn} / \mathrm{C}$ inverse opal electrode fabrication. Here, within the thick electrodes, the Ni scaffold and $\mathrm{SiO}_{2}$ were retained to provide strength to the free-standing electrode.

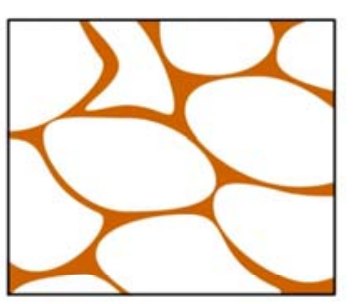

Thick 3D Ni scaffold
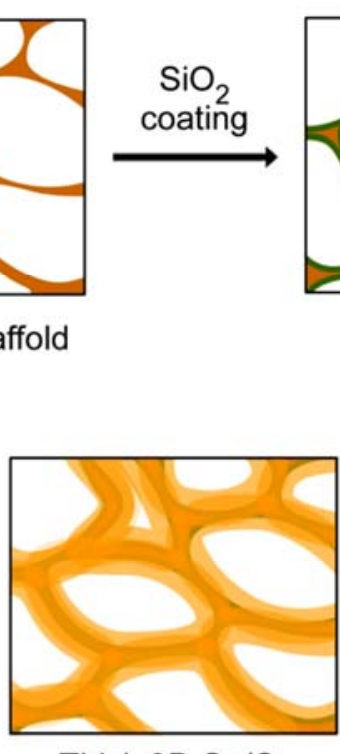

Thick 3D Sn/C composite on $\mathrm{Ni@SiO} 2$

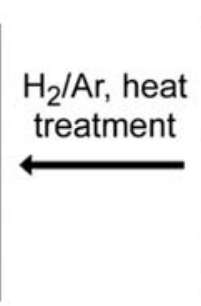

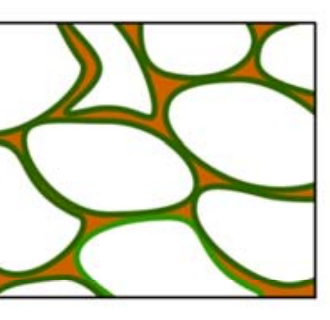

$\mathrm{Ni@SiO} 2$

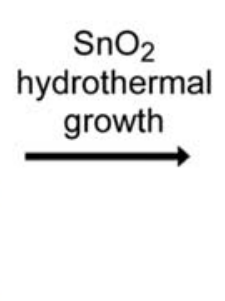

$\mathrm{SnO}_{2}$-coated Ni@SiO 2

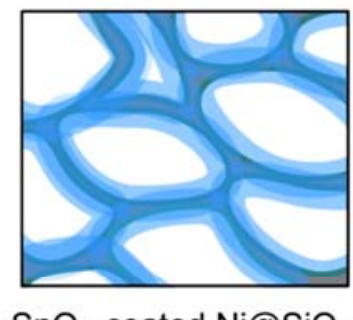

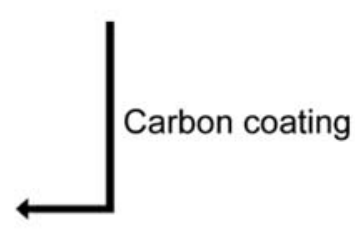

Figure S7. Illustration of the fabrication process for the $100 \mu \mathrm{m}$-thick Sn-based composite anodes. 

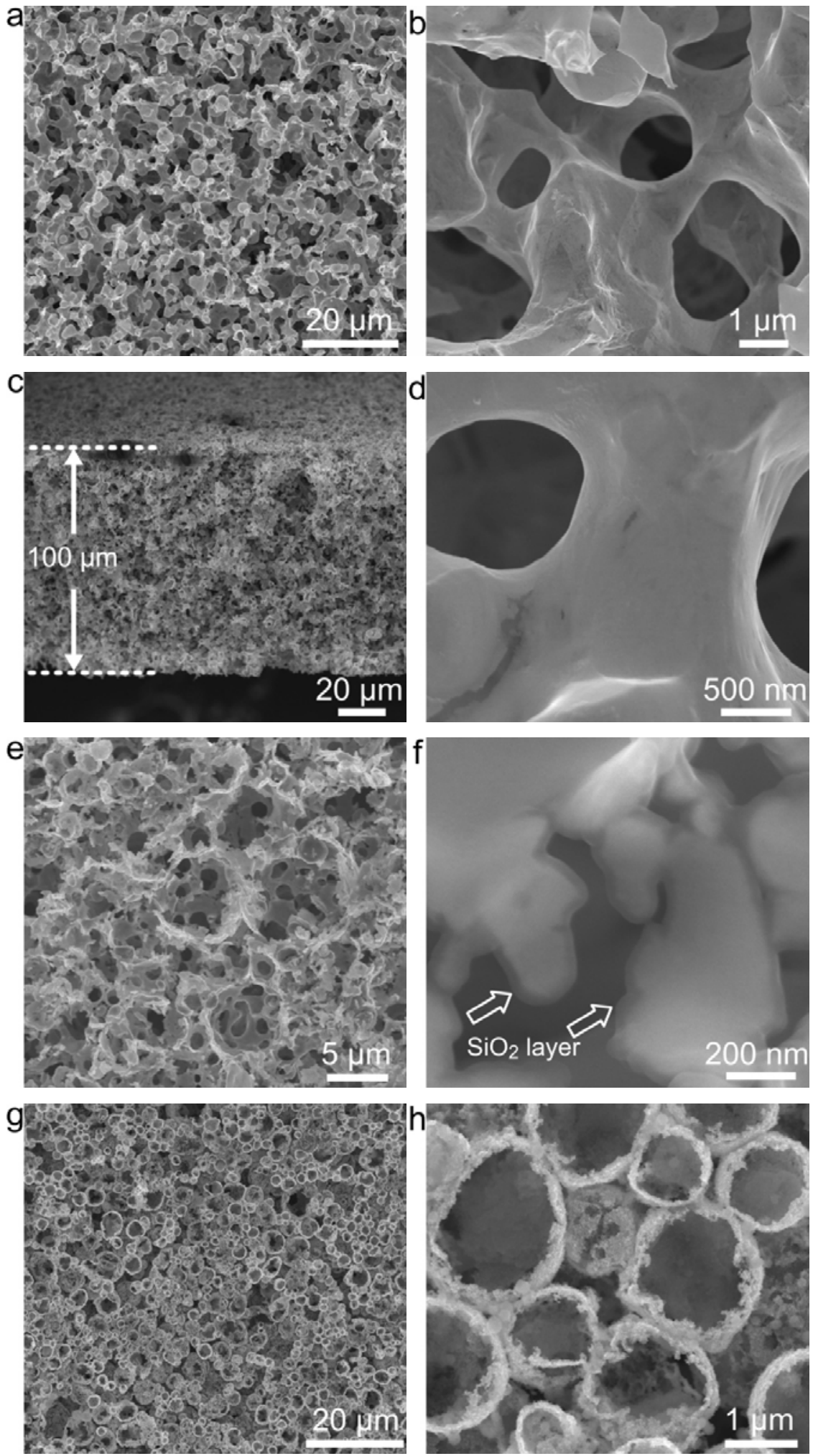

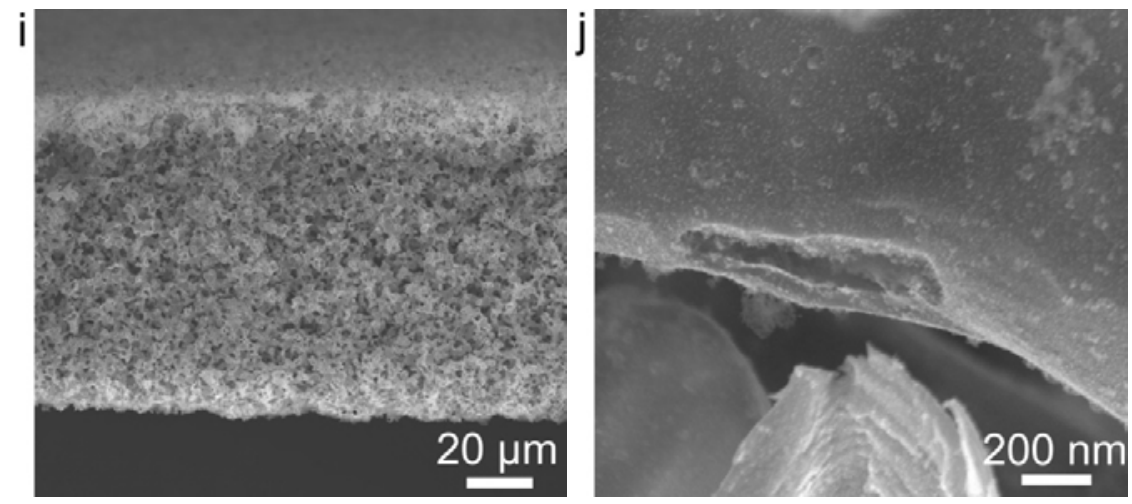

Figure S8. (a), (b) Top-view and (c), (d) cross-sectional SEM images of the 3D porous Ni scaffold. (e), (f) Top-view SEM images of the $\mathrm{SiO}_{2}$-coated Ni scaffold. (g), (h) Top-view and (i), (j) cross-sectional SEM images the fabricated thick $\mathrm{Sn} / \mathrm{C}$ composite anode on a $\mathrm{Ni@SiO} 2$ scaffold.
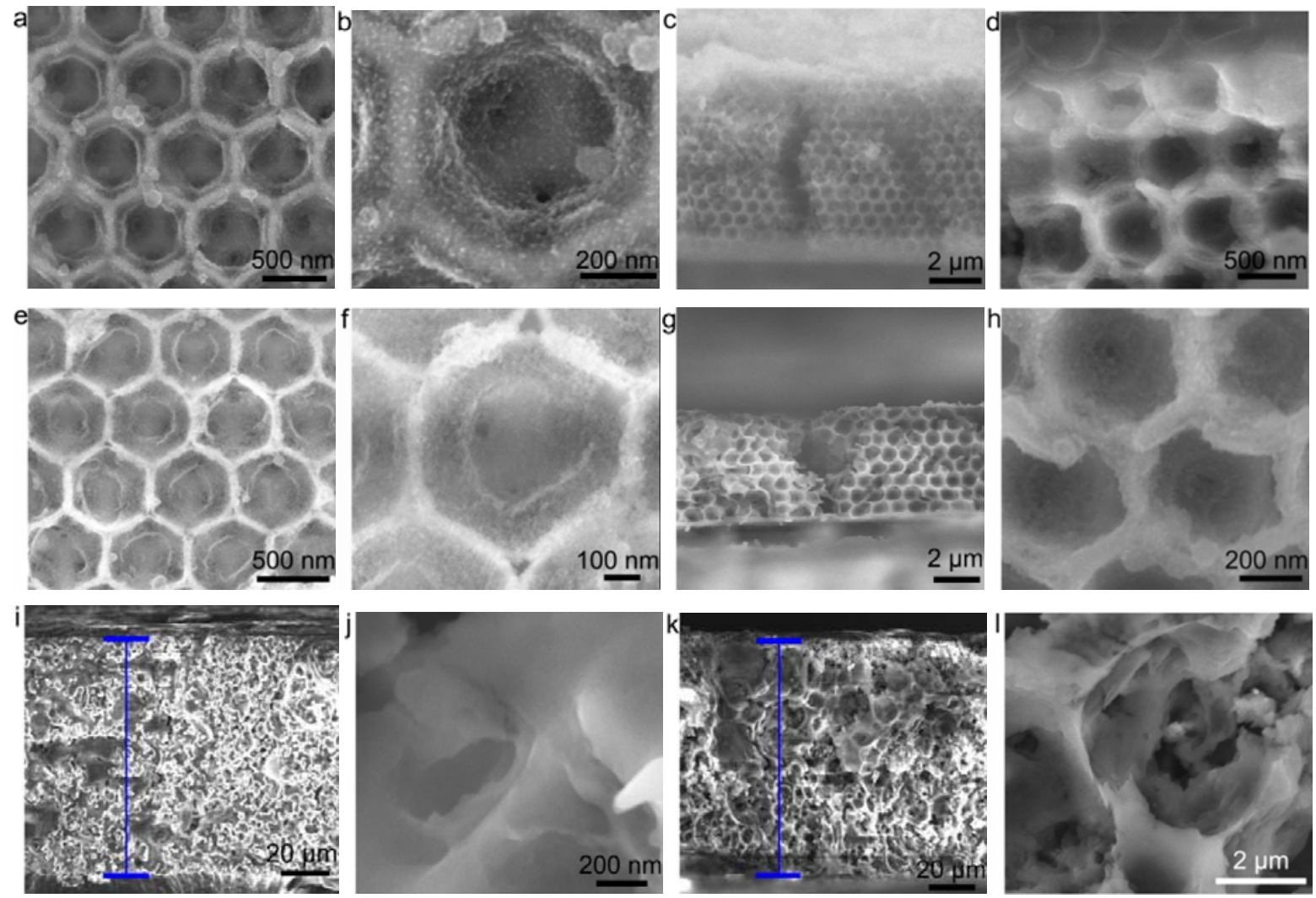

Figure S9. (a), (b) Top-view and (c), (d) cross-sectional SEM images of the 3D sphere-caged Sn/C 
anode after lithiation. (e), (f) Top-view and (g), (h) cross-sectional SEM images of the Sn/C anode after delithiation. Cross-sectional SEM images of the $\sim 100 \mu \mathrm{m}$ thick Sn/C anode after (i), (j)

lithiation and (k), (l) delithiation. Blue scale bars show the same length in both images.

\section{References:}

(1) Dresselhaus, M. S.; Jorio, A.; Saito, R. Annu. Rev. Condens. Matter Phys. 2010, 1, 89-108. 